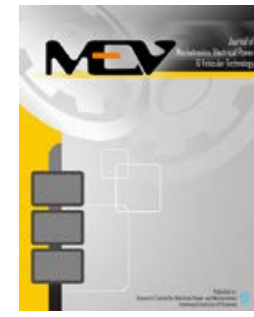

Journal of Mechatronics, Electrical Power, and Vehicular Technology

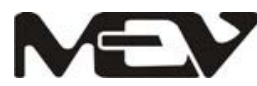

\title{
Numerical investigation of the effect of triangle strut in vertical axis wind turbine (VAWT)
}

\author{
Tri Admono ${ }^{\mathrm{a}, *}$, Yoyon Ahmudiarto a , Amma Muliya Romadoni ${ }^{\mathrm{a}}$, \\ Iman Abdurahman ${ }^{\mathrm{a}}$, Agus Salim ${ }^{\mathrm{a}}$, Teguh Tri Lusijarto ${ }^{\mathrm{a}}$, \\ Mochammad Agoes Mulyadi ${ }^{b}$ \\ ${ }^{a}$ Research Centre for Electrical Power and Mechatronics, Indonesian Institute of Sciences (LIPI) \\ Komplek LIPI JI. Sangkuriang, Building 20, Bandung 40135, Indonesia \\ ${ }^{b}$ Department of Aeronautics and Astronautics, Bandung Institute of Technology \\ JI. Ganesa No.10, Lb. Siliwangi, Bandung, West Java, 40132, Indonesia
}

Received 23 September 2020; Accepted 11 November 2020; Published online 22 December 2020

\begin{abstract}
Strut is used in vertical axis wind turbine (VAWT) to restraint the framework. In this study, struts are analyzed to show the pressure losses in VAWT. ANSYS computational fluid dynamics (CFD) software is used to investigate triangle strut in VAWT. This study aims to show a CFD simulation of struts, which affects the aerodynamic of VAWT. In CFD software, the aerodynamic of VAWT can be analyzed in terms of pressure losses in the struts. The simulation method starts by making a struts model, then meshing and setting up ANSYS's boundary conditions. The last iteration runs in ANSYS until convergence. Our results show the percentage of pressure losses with the variation of the angle of wind $0^{\circ}, 20^{\circ}, 40^{\circ}$, and $60^{\circ}$ are $0.67 \%, 0.52 \%, 0.48 \%$, and $0.52 \%$. The effect of triangle strut in VAWT did not affect the wind flow to the VAWT blade. The results also indicated that the triangle strut could be applied in the multi-stage of VAWT system.
\end{abstract}

(C2020 Research Centre for Electrical Power and Mechatronics - Indonesian Institute of Sciences. This is an open access article under the CC BY-NC-SA license (https://creativecommons.org/licenses/by-nc-sa/4.0/).

Keywords: vertical axis wind turbine (VAWT); triangle strut; computational fluid dynamics (CFD); pressure losses.

\section{Introduction}

Nowadays, people are interested in using renewable energy because of its zero emissions and also reduce the dependence on fossil fuels [1]. With the growth of the demand for application in renewable energy, the wind turbine is implemented in the urban environment. However, the design of the wind turbine must be considered, especially the design of the strut [2].

Vertical axis wind turbine (VAWT) different from the horizontal axis wind turbine (HAWT) in rotor kinematics, rotor aerodynamics, and wake structure [3]. In the wake structure, a strut keeps the wind turbine stable in the framework. The strut of VAWT is a crucial component. As such, an engineer must consider the strut to have a good performance for VAWT. In the vertical axis turbine, commonly there are two configurations of the turbine, namely open-

\footnotetext{
* Corresponding Author. Tel: +62-813-2059-4714

E-mail address: tri.admono@yahoo.com
}

ended and squirrel-wheel design, as shown in Figure 1 [4]. In the open-ended type usually used in the wind turbine, the blade is connected to the turbine axis using struts. The number of struts to support the blades varies, depending on the geometry of the turbine, length, radius, solidity, and blade size. On the other hand, squirrel-wheel type, or closed-type with the circle in shape usually used in marine turbines. In any case, both open-ended and squirrelwheel can be applied in the wind or marine turbine.

Investigating VAWT strut is substantial because it is related to the aerodynamics of wind turbines. Any interference can affect the pressure losses of VAWT,

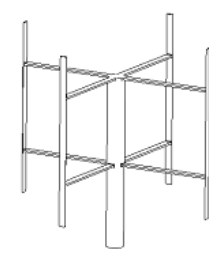

(a)

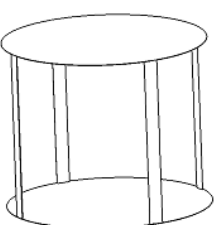

(b)
Figure 1. (a) Open-ended type; (b) Squirrel-wheel type 
which is a crucial factor in the performance of VAWT. When the wind flows to the VAWT blade, the velocity and pressure change due to the strut surrounding the blade. Therefore, the aerodynamic effect of the strut needs to be investigated when analyzing and designing struts [5][6][7].

Computational fluid dynamics (CFD) is a numerical tool used to solve aerodynamic phenomena. CFD can accurately predict the phenomenon between the strut and its surrounding. Many studies have been applied to evaluate the aerodynamic models for VAWT that can predict aerodynamic performance [8][9][10]. In this study, the ANSYS Fluent CFD software is used to analyze triangle strut in VAWT utilizing the pressure losses caused by a strut. A triangle strut on the top and bottom side was chosen because it can be applied by a multi-stage VAWT system. We assumed that CFD simulation can be executed in a short period using physical experiments and tests to get the data, such as pressure loss, velocity, etc.

This research was conducted between the Research Centre for Electrical Power and Mechatronics, Indonesian Institute of Sciences (LIPI), and the Department of Aeronautics and Astronautics, Bandung Institute of Technology (ITB). Results of the CFD simulation will be applied to the design of VAWT, located in Sumedang.

\section{Materials and Methods}

This research focused on analyzing the effect of triangle strut in VAWT pressure losses. ANSYS computational fluid dynamics (CFD) method applied in this case. Generally, CFD consist of several governing equations, such as continuity equations, Navier-Stokes equations, and energy equations [11]. The simulation is performed in 2D and 3D. Furthermore, the object is considered by steadystate, incompressible, isothermal, and viscous flow. The domain was stationary and turbulent model kepsilon applied in simulation.

The continuity equation is the fundamental law of the mass conservation equation. The law of mass conservation is defined as a change in mass in the volume control (CV) equal to the net rate of mass entering CV [12]. The conservation equation for mass in integrals is as follows:

$\frac{\partial}{\partial t} \int_{C V} \rho \cdot d V+\int_{C S} \rho \mathrm{u} \cdot \vec{n} \cdot d \mathrm{~A}=0, \forall \mathrm{v} \in \mathrm{R}$

Equation (1) can be converted to the differential using Gauss divergence theorem:

$\dot{\rho}+\nabla(\rho \mathrm{u})=0$

where $\rho$ is density $\left(\mathrm{kg} / \mathrm{m}^{3}\right), \mathrm{u}$ is flow velocity $(\mathrm{m} / \mathrm{s})$, and $\nabla$ is density divergence term (differential operator)

$\nabla=\frac{\partial}{\partial x}+\frac{\partial}{\partial y}+\frac{\partial}{\partial z}$

The equation in incompressible viscous flow described in the Navier-Stokes equation:

$\frac{\partial \bar{u}_{i}}{\partial t}+\bar{u}_{j} \frac{\partial \bar{u}_{i}}{\partial x_{j}}=-\frac{\partial \bar{p}}{\partial x_{i}}+v \frac{\partial^{2} \bar{u}_{i}}{\partial x_{j} \partial x_{j}}-\frac{\partial \tau_{i j}}{\partial x_{j}}$
The tensor of the velocity vector is $\tau_{i j}$

$\tau_{i j}=\overline{\hat{u}_{\imath} \dot{u}_{J}}$

The velocity of the fluid must be equal to zero because no-slip condition for a viscous fluid.

$\frac{\partial \bar{u}_{i}}{\partial x_{i}}=0$

where $u_{i}$ is fluid velocity $(\mathrm{m} / \mathrm{s}), \mathrm{p}$ is pressure $(\mathrm{Pa})$, and $v$ is kinematic viscosity $\left(\mathrm{m}^{2} / \mathrm{s}\right)$.

In this study, VAWT type with Darrieus blade installed with triangle struts. Generally, in the Darrieus model, the radial arms connect the shaft at one end and the inner side of the turbine blade at another one [13]. So, the velocity inlet can affect the aerodynamic of the VAWT from the radial arm and the shaft. Figure 2 shows the Darrieus blade with the flow of inlet velocity.

Figure 3 shows the pressure distribution of the cylinder shape. In the cylinder shape from the area of shaft or strut, there is a pressure loss affected by inlet pressure [14]. The percentage of pressure losses can be calculated from data between inlet and reference pressure:

$\frac{P_{\text {inlet }}-P_{\text {reference }}}{P_{\text {reference }}} \times 100 \%=$ percentage of pressure losses $(7)$

There are a few steps required before the CFD calculation. In the beginning, the model is developed before the mesh is carefully generated to ensure the quality of the simulation. The next step is to set the boundary conditions and conditions for the iterations. Lastly, the computation is started through iterations until the solution is found when it reaches the pre-defined convergence criteria [15]. Figure 4 shows the step of the simulation.

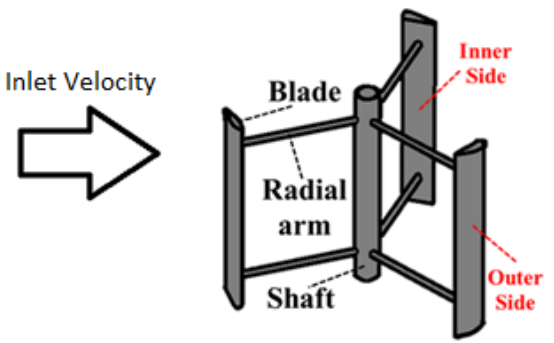

Figure 2. Inlet velocity to the VAWT Darrieus blade

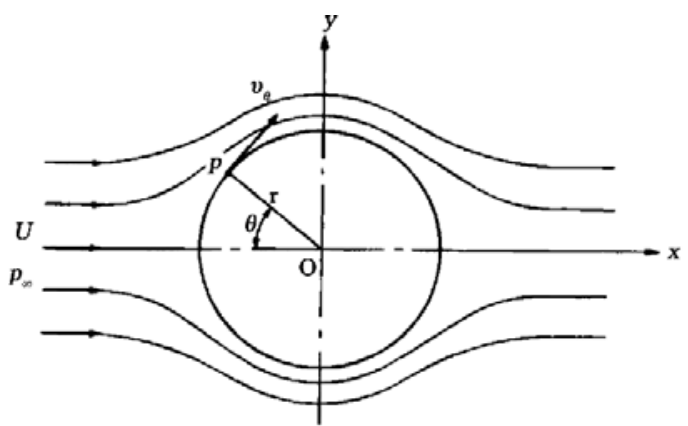

Figure 3. Pressure distribution around the cylinder shape

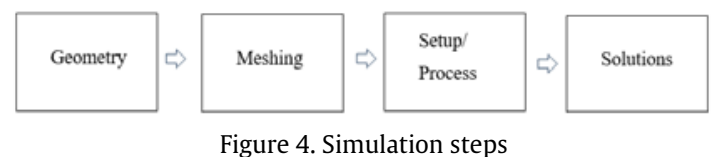




\section{A. Geometry}

The triangle strut is made for a multi-stage vertical axis wind turbine (VAWT) which can be installed portable in the urban or rural area. Therefore, a special design is needed, different from the general strut. In this research, the design of the strut on the top and bottom is a triangle shape. So, the stand frame follows to support the struts. Figure 5 shows the design of the triangle strut with the blade.

Figure 6 shows the dimension of the strut. The diameter of the strut support is $90 \mathrm{~mm}$. Each blade stage has a space of $3000 \mathrm{~mm}$. In the middle, there are $500 \mathrm{~mm}$ of space for the multi-stage VAWT generator. In this study, simulation progress only in a single stage without the blade, to focus on triangle strut.

\section{B. Meshing \& processing}

Meshing is a fundamental process in CFD simulation to define finite volume in the object. Figure 7 shows the 2D mesh structure in object simulation. Boundary condition set up at inlet, outlet, and wall. To make sure the quality of the mesh,
Figure 8 shows graphic distribution from 0.2 to 1 . The quality mesh is excellent because it is evenly distributed and using triangular/tetrahedral. The total of number elements is 11300 .

In this research, CFD simulation used ANSYS Fluent package. The object is simulated under the steady-state condition and the turbulent model used is $\mathrm{k}$ epsilon. The turbulent flow regime is subsonic. The reference pressure is 1 atm and the wind velocity is $6 \mathrm{~m} / \mathrm{s}$. The flow regime is subsonic. The angle of wind direction varies from $0,20,40$, and 60 degrees. Firstly, the simulation process is carried out in a $2 \mathrm{D}$ object, before for comparison purposes, the simulation is run with the $3 \mathrm{D}$ object.

\section{Results and Discussions}

\section{A. Results of the 2D strut}

Figure 9 shows the contour of the velocity vector and total pressure in a 2D object. From Figure 9a, the contour of the velocity vector at 0 degrees of wind direction did not distract the aerodynamic of the system. Maximum velocity of $12.55 \mathrm{~m} / \mathrm{s}$ distracts the little area in the circle point of the strut. The triangle strut does not produce a big distraction to the

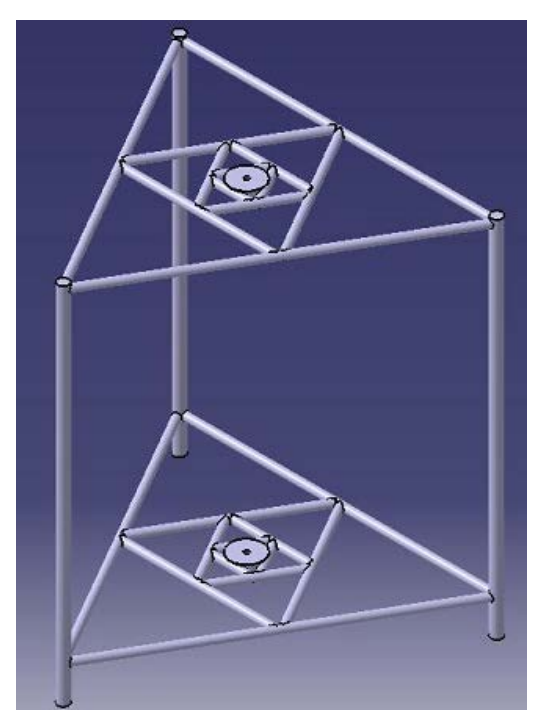

(a)

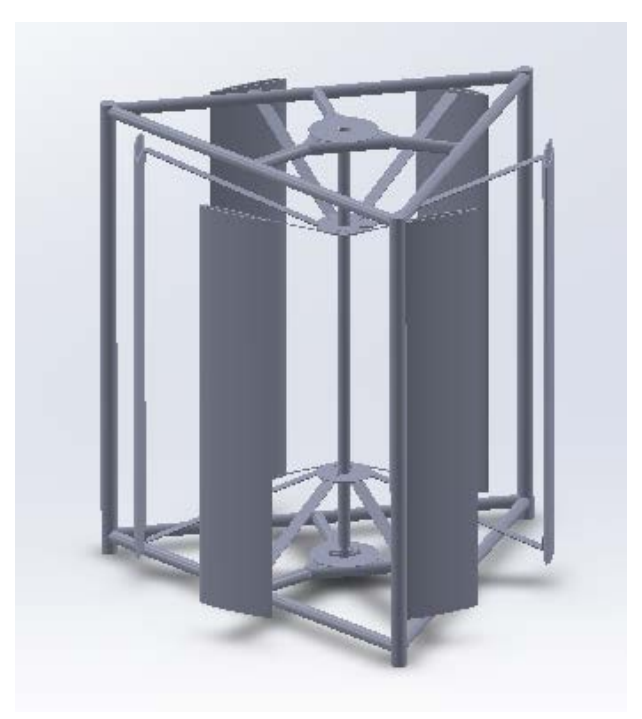

(b)

Figure 5. (a) Initial triangle strut design; (b) Triangle strut design with blade turbine

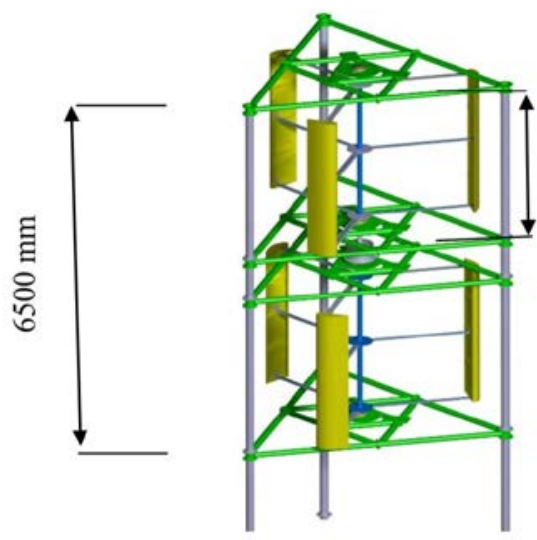

(a)

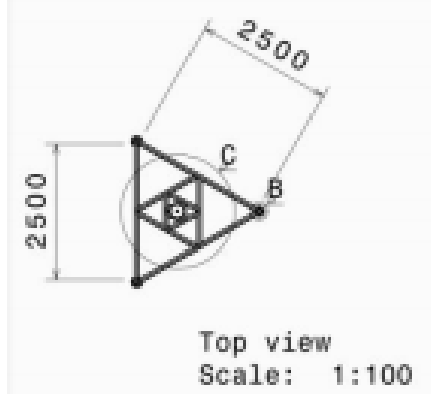

(b)

Figure 6. Multi-stage triangle strut: (a) isometry view; (b) top view 


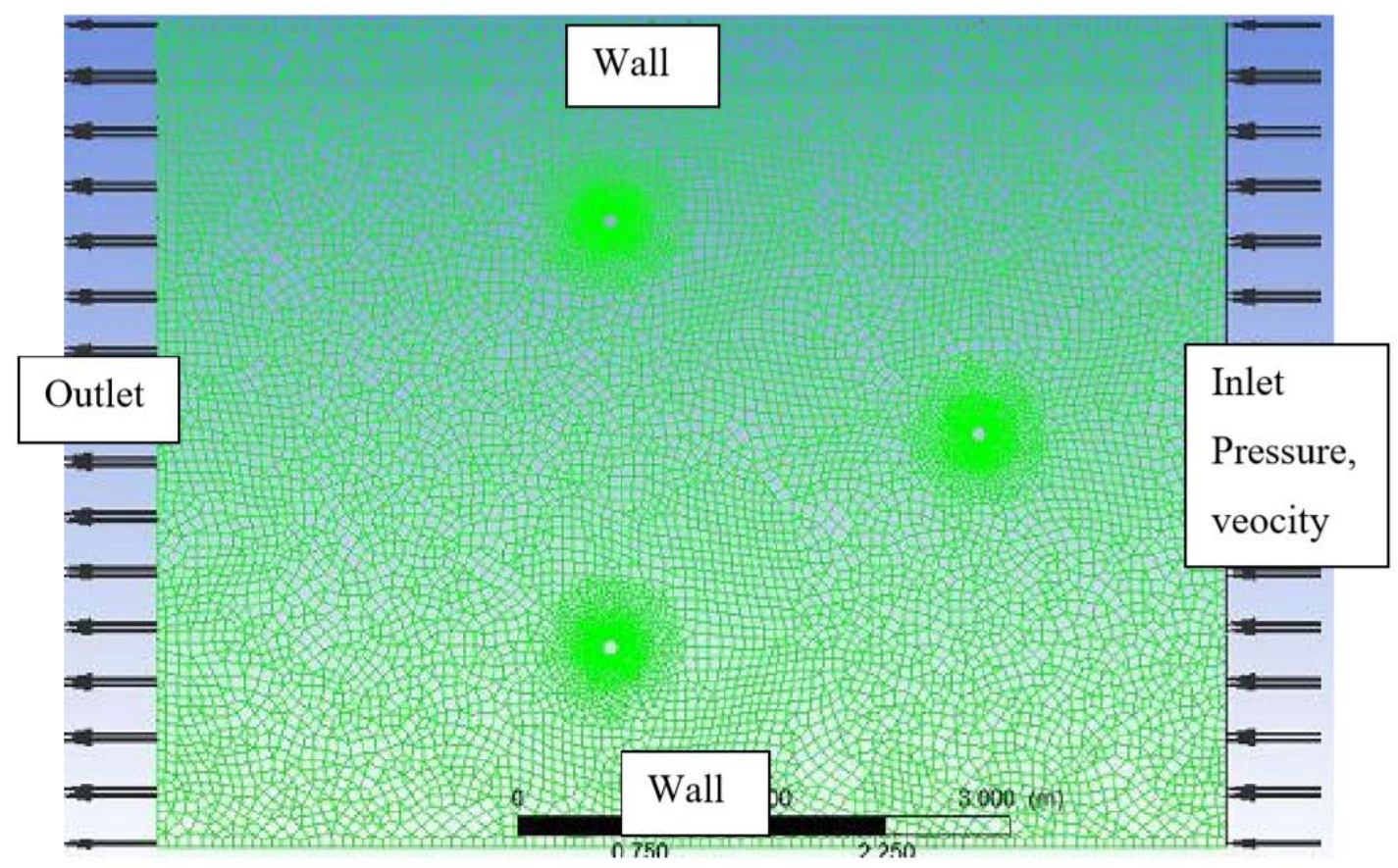

Figure 7. Mesh 2D structure of VAWT

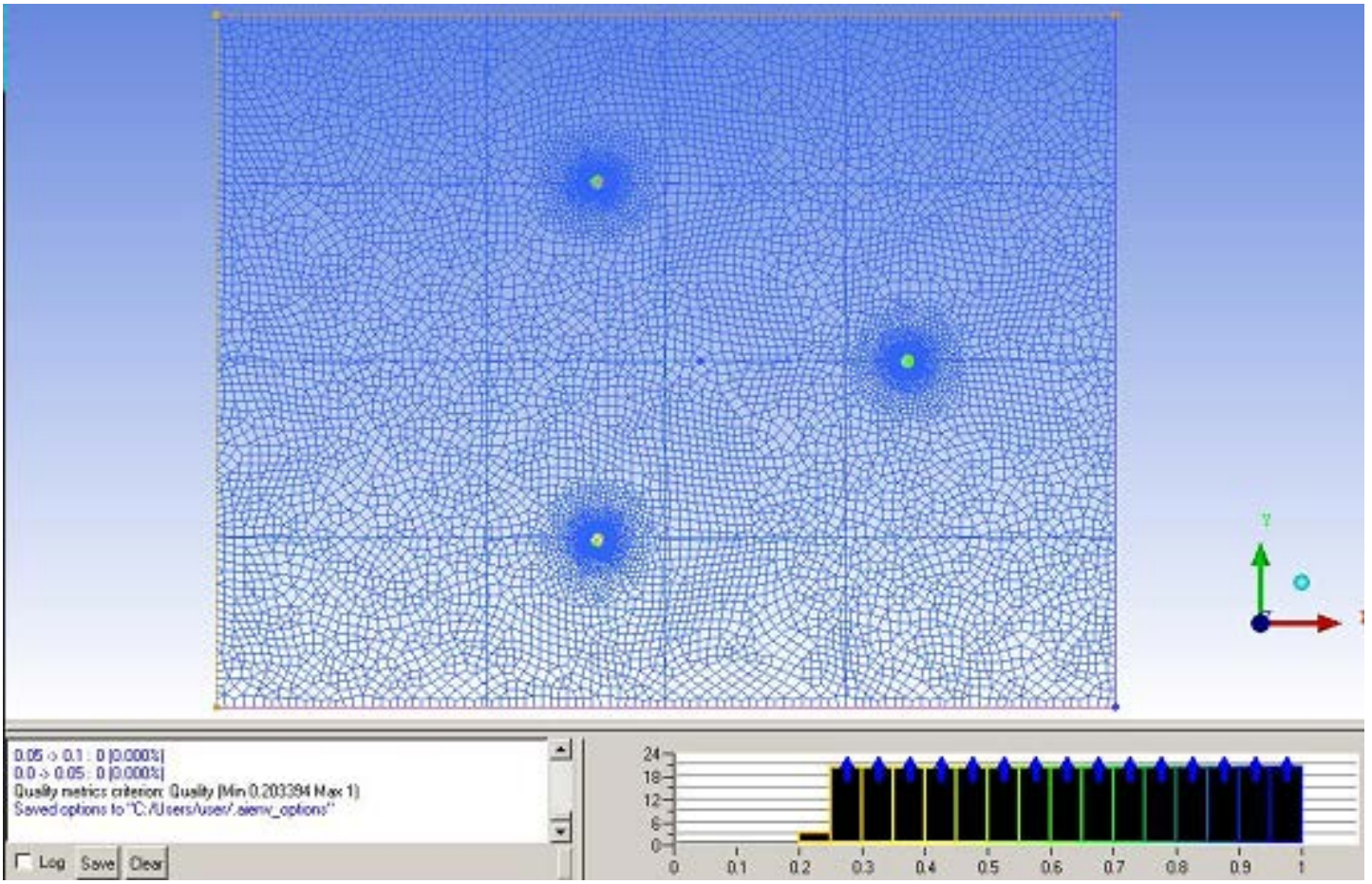

Figure 8. Quality of the mesh

Table 1.

Pressure losses at variations of degree in 2D

\begin{tabular}{ccccc}
\hline No & $\begin{array}{c}\text { Angle of wind direction } \\
\text { (Degree) }\end{array}$ & $\begin{array}{c}\text { Inlet total pressure } \\
(\mathrm{Pa})\end{array}$ & $\begin{array}{c}\text { Total pressure } \\
\boldsymbol{A}_{\text {ref }}(\mathrm{Pa})\end{array}$ & $\begin{array}{c}\text { Percentage of losses } \\
(\%)\end{array}$ \\
\hline 1. & 0 & 29.3858 & 29.2293 & 0.53 \\
2. & 20 & 29.4473 & 29.3472 & 0.34 \\
3. & 40 & 29.4216 & 29.2833 & 0.47 \\
4. & 60 & 29.0955 & 28.9528 & 0.49 \\
\hline
\end{tabular}

system aerodynamic. Furthermore, Figure 9b shows a small effect of the pressure. The inlet pressure is 29.3858 $\mathrm{Pa}$ and the total pressure is $29.2293 \mathrm{~Pa}$. From the data, the percentage of pressure loss is
$0.53 \%$. Table 1 presents the variation of pressure losses from different angles of wind. Small difference data between the inlet and total pressure in 2D simulation indicate that are good in the results. 


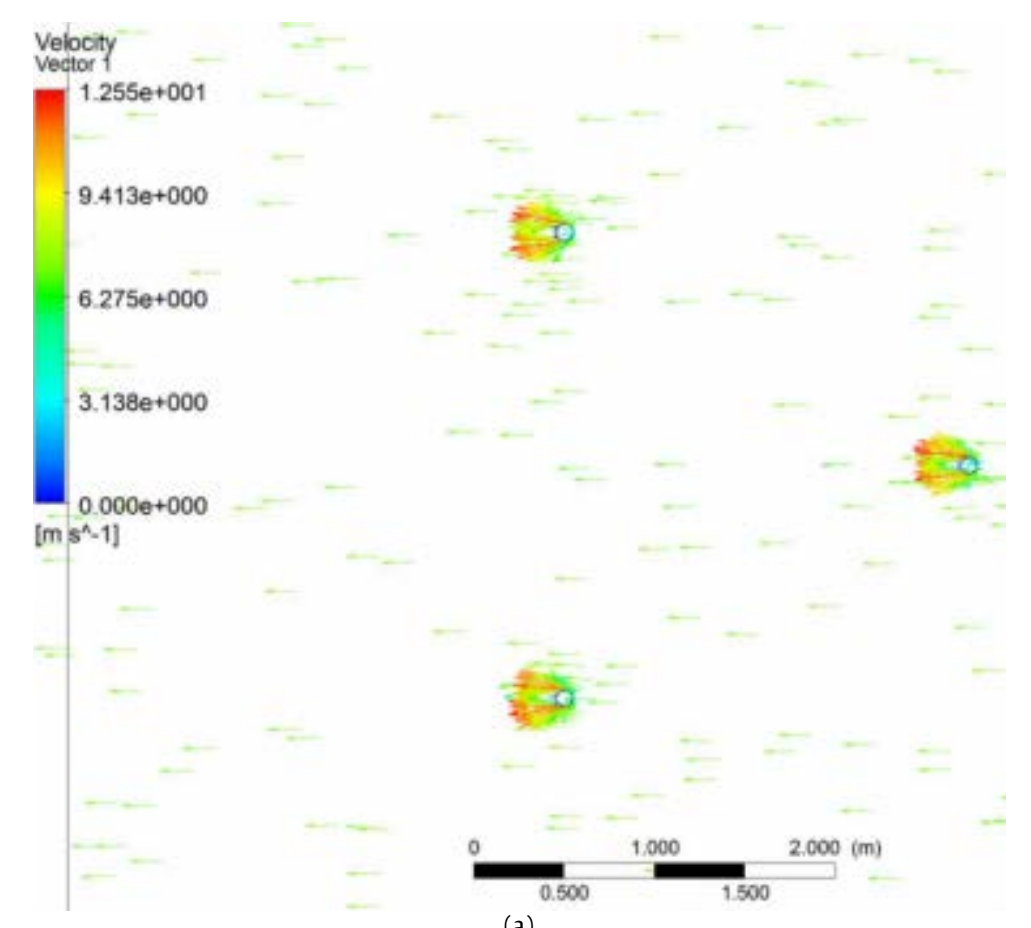

(a)

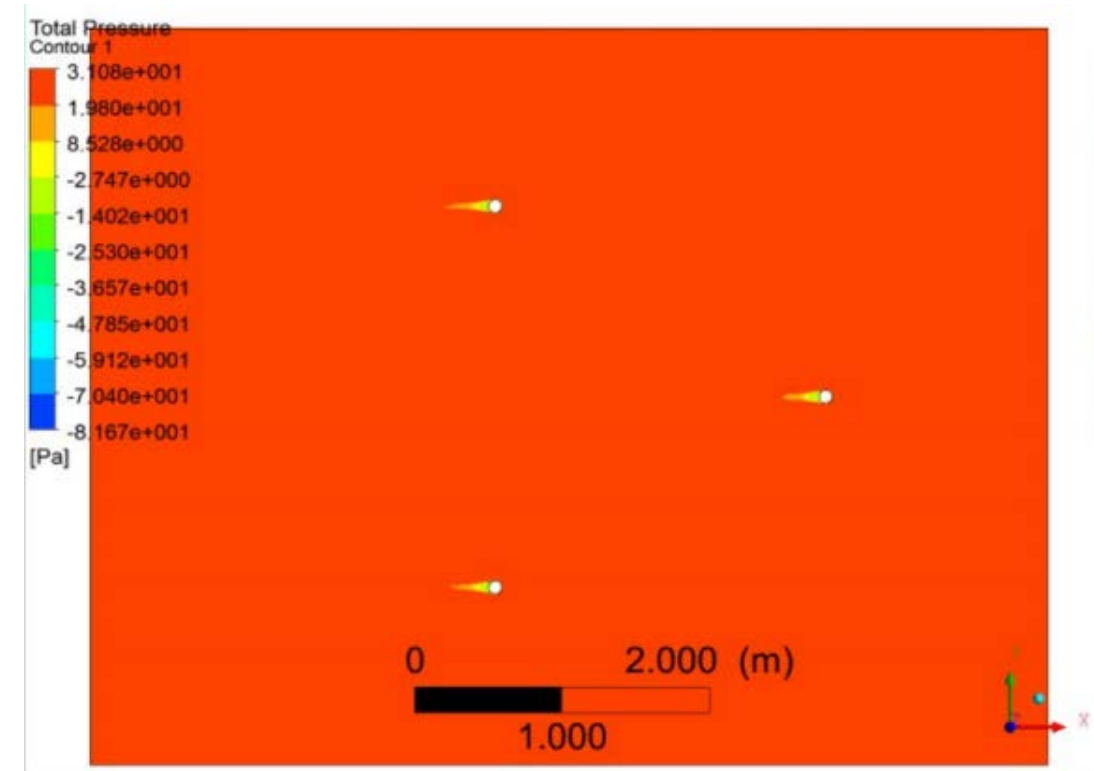

(b)

Figure 9. The contour of: (a) velocity vector; and (b) pressure in 2D object

Table 2.

Pressure losses at variations of degree in 3D

\begin{tabular}{ccccc}
\hline No & $\begin{array}{c}\text { Angle of wind direction } \\
\text { (Degree) }\end{array}$ & $\begin{array}{c}\text { Inlet total pressure } \\
(\mathrm{Pa})\end{array}$ & $\begin{array}{c}\text { Total pressure } \\
\boldsymbol{R e f}(\mathrm{Pa})\end{array}$ & $\begin{array}{c}\text { Percentage of losses } \\
(\%)\end{array}$ \\
\hline 1. & 0 & 29.83 & 29.63 & 0.67 \\
2. & 20 & 29.96 & 29.81 & 0.52 \\
3. & 40 & 29.76 & 29.62 & 0.48 \\
4. & 60 & 29.45 & 28.29 & 0.52 \\
\hline
\end{tabular}

\section{B. Results of 3D strut}

Figure 10 shows the velocity vector and total pressure in a 3D object. Figure 10a shows the contour of the velocity vector at 0 degrees of wind direction with the maximum velocity at $12.87 \mathrm{~m} / \mathrm{s}$. The triangle strut does not produce a big distraction of aerodynamic to the system, except in the little area of the strut. Furthermore, Figure 10b shows the small effect of the pressure, that is the Inlet pressure of 29.83 Pa and the total pressure of $29.63 \mathrm{~Pa}$. From the data, the percentage of pressure loss is $0.67 \%$. Table 2 presents the variation of data of pressure losses from a different angle of wind direction. Small difference data between the inlet and total pressure in $3 \mathrm{D}$ simulation indicate that this is a good sign in the results. 


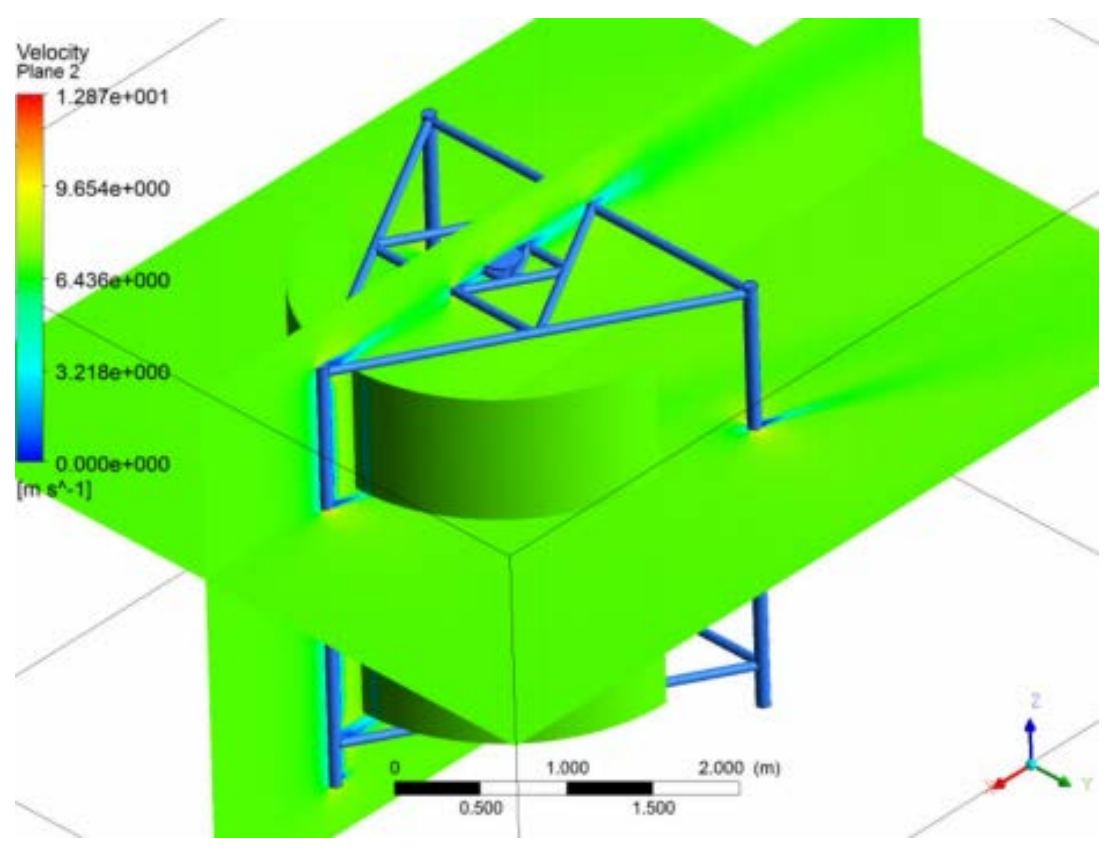

(a)

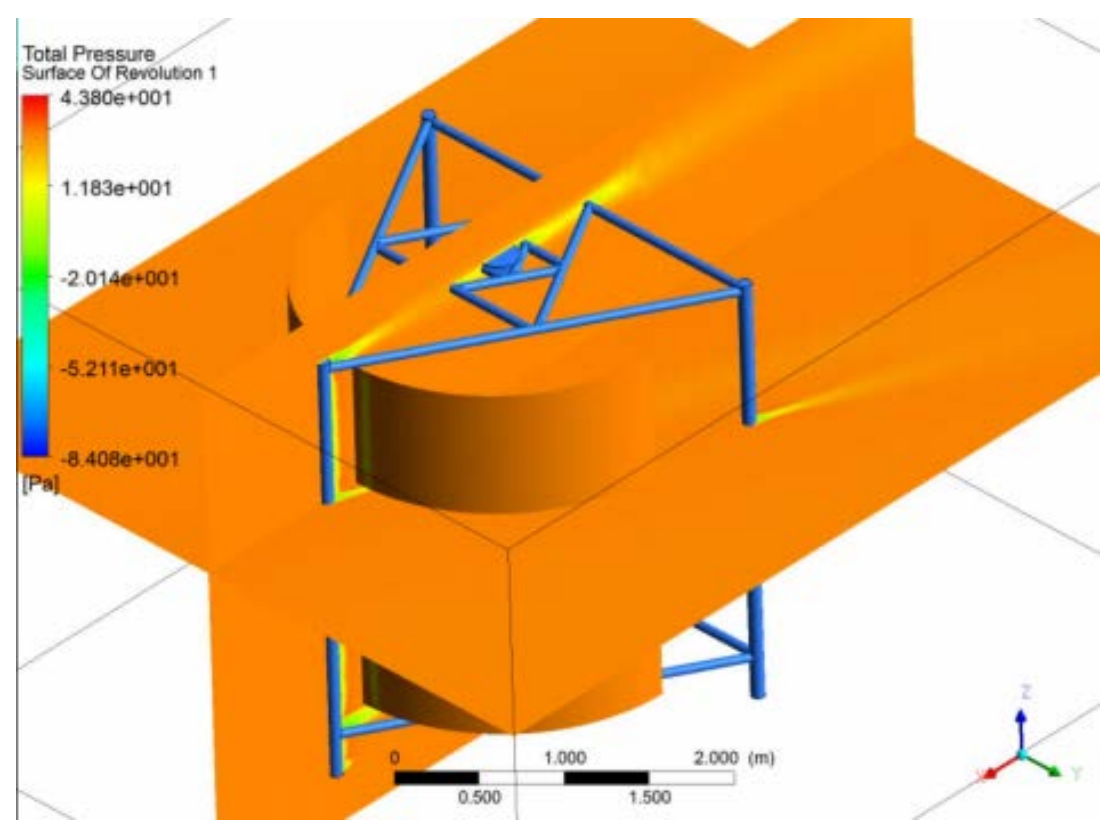

(b)

Figure 10. The contour of: (a) velocity vector; (b) pressure in 3D object

Table 3.

Comparison of pressure losses 2D and 3D

\begin{tabular}{ccccc}
\hline No & $\begin{array}{c}\text { Angle of wind direction } \\
\text { (Degree) }\end{array}$ & $\begin{array}{c}\text { Percentage of losses 2D } \\
(\%)\end{array}$ & $\begin{array}{c}\text { Percentage of losses 3D } \\
(\%)\end{array}$ & $\begin{array}{c}\text { Difference } \\
(\%)\end{array}$ \\
\hline 1. & 0 & 0.53 & 0.67 & 0.14 \\
2. & 20 & 0.34 & 0.52 & 0.18 \\
3. & 40 & 0.47 & 0.48 & 0.01 \\
4. & 60 & 0.49 & 0.52 & 0.03 \\
\hline
\end{tabular}

Table 3 shows data of pressure losses comparison between $2 \mathrm{D}$ and $3 \mathrm{D}$ of triangle strut. In the angle of wind direction, 0 degrees has a difference of $0.14 \%$, which shows that the data are close. Therefore, the data are correct in 2D or 3D simulation. When the angle is 20 degrees, it has a difference of $0.18 \%$, which shows that the data are also close. In the angle of wind direction, 40 degrees has a difference of $0.01 \%$, this shows the data are almost similar. In the angle of wind directions, 60 degrees has a difference of $0.03 \%$, this shows the data are almost similar too. All of the comparison data have little difference and indicate triangle strut did not distract the aerodynamic of the VAWT system. 


\section{Conclusion}

In this research, a triangle strut design for multistage VAWT is investigated using computational fluid dynamics (CFD) software. The main goal is to analyze the effect of triangle strut design on the aerodynamic VAWT system. From CFD simulation software, little distractions are surrounding the strut and did not affect the wind flow to the VAWT blade. At the angle of wind direction $0,20,40$, and 60 degrees, percentage of pressure losses are $0.67 \%$, $0.52 \%, 0.48 \%$, and $0.52 \%$. Therefore, triangle strut is suitable to be applied in multi-stage vertical axis wind turbine (VAWT).

\section{Acknowledgement}

This research is supported by the Research Centre for Electrical and Mechatronics, Indonesia Institute of Science (LIPI) Bandung, Indonesia. We are also immensely grateful to all lecturers of the Department of Aeronautics and Astronautics, Bandung Institute of Technology, Indonesia, who is joined in this research.

\section{Declarations}

\section{Author contribution}

T. Admono, Y. Ahmudiarto, A.M. Romadoni, and M.A. Mulyadi contributed equally as the main contributor of this paper. All authors read and approved the final paper.

\section{Funding statement}

This research did not receive any specific grant from funding agencies in the public, commercial, or not-forprofit sectors.

\section{Conflict of interest}

The authors declare no conflict of interest.

\section{Additional information}

No additional information is available for this paper.

\section{References}

[1] S. Siddiqui, N. Durrani, and I. Akhtar, “ Numerical study to quantify the effects of struts \& central hub on the performance of a three-dimensional vertical axis wind turbine using sliding mesh," in Proceedings of the ASME 2013 Power Conference, 2013, pp. 1- 11

[2] Y. Bazilevs, A. Korobenko, X. Deng, J. Yan, M. Kinzel, and J. O. Dabiri, " Fluid - structure interaction modeling of verticalaxis wind turbines," J. Appl. Mech., vol. 81, no. August, pp. 18, 2014.

[3] T. C. Hohman, L. Martinelli, and A. J. Smits, “ The effects of inflow conditions on vertical axis wind turbine wake structure and performance," J. Wind Eng. Ind. Aerodyn., vol. 183, no. October, pp. 1- 18, 2018.

[4] A. Goude, S. Lundin, and M. Leijon, “ A parameter study of the influence of struts on the performance of a vertical-axis marine current turbine," in Proceedings of the 8th European Wave and Tidal Energy Conference, 2009, pp. 477- 483.

[5] P. Bachant and M. Wosnik, " Performance and near-wake measurements for a vertical axis turbine at moderate Reynolds number," in Proceedings of the ASME 2013 Fluids Engineering Division Summer Meeting, 2013, pp. 1- 9.

[6] A. R. Davari, " Wake structure and similar behavior of wake profiles downstream of a plunging airfoil," Chinese J. Aeronaut., no. June, pp. 1- 13, 2017.

[7] S. Hanchi, T. Benkherouf, M. Mekadem, and H. Oualli, “ Wake structure and aerodynamic characteristics of an autopropelled pitching airfoil," J. Fluids Struct., vol. 39, pp. 275291, 2013.

[8] H. Lee and D. Lee, “ Numerical investigation of the aerodynamics and wake structures of horizontal axis wind turbines by using nonlinear vortex lattice method," Renew. Energy, 2018.

[9] A. Posa, C. M. Parker, M. C. Leftwich, and E. Balaras, "Wake structure of a single vertical axis wind turbine," Int. J. Heat Fluid Flow, vol. 0, pp. 1- 10, 2016.

[10] Y. Ahmudiarto, A. M. Romadoni, T. B. Karyanto, T. Admono, B. Nugroho, R. C. Chin, and A. Budiyono, " Performance Analysis of Novel Blade Design of Vertical Axis Wind Turbine," in 2019 International Conference on Sustainable Energy Engineering and Application (ICSEEA), 2019, pp. 175- 181.

[11] T. Wah-yen, Y. Asako, N. Azwadi, C. Sidik, and G. Rui-zher, " Governing equations in computational fluid dynamics: derivations and a recent review," Prog. Energy Environ., no. June, pp. 1- 19, 2017.

[12] Y. Wei, “ The development and application of CFD technology in mechanical engineering The development and application of CFD technology in mechanical engineering," in IOP Conf. Series: Materials Science and Engineering, 2017, pp. 1- 9.

[13] W. Liu and O. Xiao, " Investigation on Darrieus type straight blade vertical axis wind turbine with flexible blade," Ocean Eng., vol. 110, pp. 339- 356, 2015.

[14] S. Ogawa and Y. Kimura, "Performance improvement by control of wingtip vortices for vertical axis type wind turbine," Open J. Fluid Dyn., vol. 8, pp. 331- 342, 2018.

[15] A. Rezaeiha, H. Montazeri, and B. Blocken, “ Towards accurate CFD simulations of vertical axis wind turbines at di fferent tip speed ratios and solidities: Guidelines for azimuthal increment, domain size and convergence," Energy Convers. Manag., vol. 156, no. October 2017, pp. 301- 316, 2018. 